\title{
Strain Behavior of Backfill Soil in Rigid Faced Reinforced Soil Walls Subjected to Seismic Excitation
}

\author{
Arup Bhattacharjee $^{1}$ A. M. Krishna ${ }^{2}$
}

Received: 2 January 2015/Accepted: 1 April 2015/Published online: 15 April 2015

(C) Springer International Publishing AG 2015

\begin{abstract}
The reinforced soil walls offer an excellent solution to the problems related to the earth retaining structures, especially under seismic condition. This paper presents the strain behavior of backfill soil subjected to seismic excitation. Full height concrete faced reinforced soil retaining wall which is termed as rigid faced reinforced soil retaining wall is considered. Numerical models of shaking table tests on full height rigid faced walls are simulated using FLAC $^{3 \mathrm{D}}$ and validated with the laboratory test results. The octahedral strains developed on backfill soil during the dynamic excitations are determined from the numerical simulations and analyzed. Two types of strained zones are observed: high strain zone near the wall facing and low strained zone extending into the retained backfill indicating localized displacements near the facing. Parametric studies are also conducted to observe the behavior of soil strains for different reinforcement configurations and backfill soils. These parameters have marginal effect on strain behavior. The results indicate that the facing modulus affects the response of rigid faced walls.
\end{abstract}

Keywords Rigid faced reinforced soil retaining wall . Numerical modeling · Seismic excitation · Octahedral shear strain

Arup Bhattacharjee

bhatta_arup@yahoo.com

A. M. Krishna

amurali@iitg.ernet.in

1 Department of Civil Engineering, Jorhat Engineering College, Jorhat 785007, India

2 Department of Civil Engineering, Indian Institute of Technology Guwahati, Guwahati, India

\section{Introduction}

The mechanically stabilized earth wall is one of the major developments in retaining structures. Application of geosynthetic reinforced soil retaining walls in major public infrastructure works are increasing tremendously due to rapid urbanization and demand for effective land utilization. The reinforced soil retaining structures have three components: backfill, reinforcement and facing system. Reinforcing materials may be of relatively inextensible metal strips or extensible polymer products like geotextiles and geogrids. Wall facing may include: wrap facing, full rigid facing, segmental block facing and modular block facing [1]. The effective performance of reinforced soil retaining walls over the conventional retaining walls during recent earthquakes are reported by many researchers [2-4]. But some researchers [5-7] are also reported failures of reinforced soil structures. The dynamic studies of reinforced soil walls can be classified into three categories: analytical studies, experimental studies and numerical studies. The analytical studies were conducted by different researchers [8-14] to know about the behavior of the reinforced soil retaining walls and to establish some design curves. The dynamic behavior of reinforced soil retaining walls and slopes was studied by various physical models tests [15-23]. The numerical simulations are useful techniques to study the behavior of reinforced retaining wall structures. A properly calibrated numerical model helps to provide insight into the problem. The seismic response of reinforced soil walls in terms of wall deformation, reinforcement load, acceleration amplification were studied by many researchers [24-32]. The response of wall subjected to earthquake after 10 years and influence of creep rate of soil and reinforcements were also studied [33, 34]. Bhattacharjee and Krishna $[35,36]$ studied the strain behavior of 
backfill soil and its influence on formation of deformation zones of wrap faced reinforced soil walls. Most of the model studies are focused on analyzing the response in terms of wall displacements, lateral pressure, acceleration amplification and reinforcement load/strain against variations in different reinforcement parameters like stiffness, spacing, length etc. and seismic excitation parameters. Very few studies are available on the strain behavior of the backfill soil and corresponding reinforcement strains and deformation zones formed at backfill of reinforced soil wall.

In the present study, a full height concrete faced reinforced soil retaining wall which is termed as rigid faced reinforced soil retaining wall is considered. A numerical model of full height rigid faced reinforced soil retaining wall is developed using three dimensional explicit finite difference program FLAC ${ }^{3 \mathrm{D}}$ and validated with laboratory test results available in literature. The behavior of wall in terms of octahedral shear strain in soil, horizontal displacements and vertical settlements of calibrated models are discussed. The behavior of full scale reinforced soil wall with reference to the zone of maximum octahedral shear strain is observed. The influence of zone of maximum octahedral shear strain on length of reinforcement, number of layer of reinforcement, reinforcement stiffness, backfill friction angle and facing stiffness are being studied.

\section{Development of Numerical Model}

\section{Target Physical Model}

Laboratory scale shaking table tests on full height rigid faced reinforced soil retaining walls described by Krishna and Latha [21] were considered as reference case for model generation. The shaking table tests were conducted on rigid faced reinforced wall model size of $700 \mathrm{~mm} \times 500 \mathrm{~mm}$ in plan area and $600 \mathrm{~mm}$ deep, constructed in a flexible laminar container. The facing was built from 12 hollow rectangular steel box sections and were bolted together with a vertical steel rod, which was fixed with the bottom plywood to represent the $600 \mathrm{~mm}$ high rigid wall with a fixed bottom condition. The backfill soil was filled in equal lifts of sand filling by pluviation method and with a layer of reinforcing material laid after each lift. The reinforcement materials were run through the bolts of the facing system to obtain a rigid connection between the wall and reinforcement. The four layers of geotextile reinforcement of length $\left(L_{\text {rein }}\right) 420 \mathrm{~mm}$ (i.e., 0.7 times the height) were used in the model. The backfill material used in the model tests was poorly graded sand having dry unit weight of $16.2 \mathrm{kN} / \mathrm{m}^{3}$ corresponding to about $65 \%$ relative density. The specific gravity of sand was 2.65 and friction angle of $43^{\circ}$. Four different reinforcement materials were used by Krishna and Latha [21]. The low strength geotextile was considered for the present study which is having ultimate tensile strength of $0.104 \mathrm{kN} / \mathrm{m}$ and secant modulus of $5.2 \mathrm{kN} / \mathrm{m}$ at $2 \%$ strain. The mass per unit area of the reinforcement material was reported as $110 \mathrm{~g} / \mathrm{m}^{2}$. A nominal surcharge of $0.5 \mathrm{kPa}$ was applied after completion of all lifts. After removing the temporary supports, model wall was subjected to 20 cycles of sinusoidal motion at different frequencies. The results obtained through various instrumentations were discussed in terms of facing horizontal deformations, acceleration amplification values. The details of the test configuration and location of various instrumentations are shown in Fig. 1. An unreinforced wall was also considered to compare the results with that of reinforced wall. The unreinforced wall configuration is similar to that of rigid-faced wall but without reinforcement.

\section{Numerical Model}

The finite difference program FLAC ${ }^{3 D}$ is used for development of numerical model. FLAC ${ }^{3 \mathrm{D}}$ is an explicit finite difference program for engineering mechanics problems [37]. Built in constitutive models are available in FLAC ${ }^{3 \mathrm{D}}$ which can be modified by using FISH programming language. The structural elements are available in FLAC $^{3 \mathrm{D}}$ to simulate the reinforcement used in physical models. Physical model construction and testing sequence, implemented in experimental procedure, are followed in development of numerical model. The shaking table is first generated as rigid foundation. The rigid wall is simulated and fixed at the bottom against lateral sliding. The backfill soil is built up in layers of equal thickness in the same sequence as physical model and reinforcements are placed on each layer. Various interfaces are also considered for proper interaction between dissimilar elements.

\section{Material Properties}

The model material properties used in the simulation are briefly discussed in the following.

\section{Wall}

The rigid wall facing is modeled as elastic material. The properties required for the elastic material model are mass density, shear modulus and bulk modulus.

\section{Backfill Material}

The backfill soil is modeled as elasto-plastic Mohr-Coulomb material coded with hyperbolic soil modulus proposed by Duncan et al. [38]. As the backfill is constructed in layer by layer, the confining pressure on each zone changes with change in height of fill, thereby the moduli. 
Fig. 1 Physical model configuration of rigid faced reinforced soil retaining wall [21]

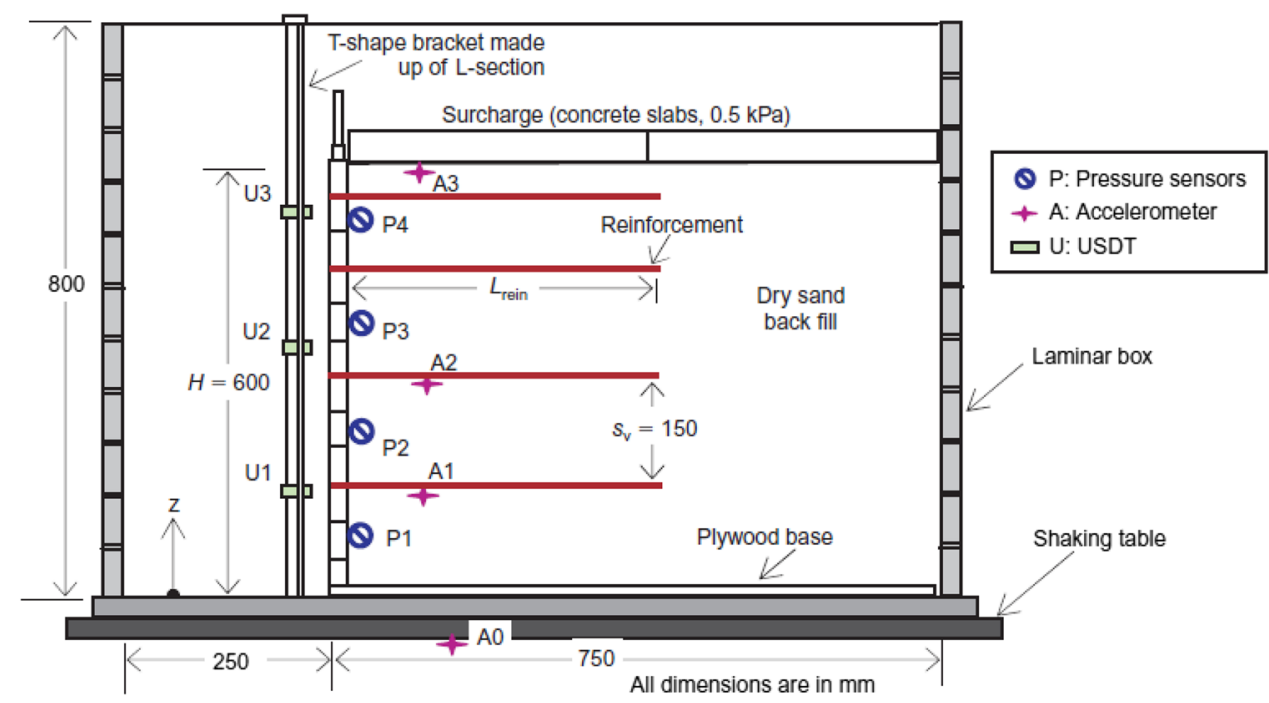

Hence, soil modulus is updated during construction by modified hyperbolic soil modulus model [38]. The stress dependent deformation modulus $\left(E_{t}\right)$ expressed by the hyperbolic equation as [38]:

$E_{t}=\left[1-\frac{R_{f}(1-\sin \phi)\left(\sigma_{1}-\sigma_{3}\right)}{2\left(c \times \cos \phi+\sigma_{3} \sin \phi\right)}\right]^{2} K_{n} \times P_{a}\left(\frac{\sigma_{3}}{P_{a}}\right)^{n}$

where $K_{n}$ is the modulus number; $n$ is the modulus exponent; $c$ is the cohesion; $\sigma_{1}$ and $\sigma_{3}$ are the major and minor effective confining stress respectively; $\phi$ is the angle of internal friction; $R_{f}$ is the failure ratio; $p_{a}$ is atmospheric pressure. A small cohesion of $0.1 \mathrm{kPa}$ is adopted to prevent premature yielding. Similar small value of apparent cohesion was also adopted by Hatami and Bathurst [39] for numerical simulation of reinforced soil walls. The hyperbolic model is incorporated by FISH subroutines [37] that update the soil modulus according to their stress condition. The shear behavior of granular soils under cyclic loading is modeled using non-linear and hysteretic constitutive relation that follows Massing rule [40] during loading and unloading cycles. In this model, the shear modulus is determined on the basis of stress and strain states that may vary considerably during simulation runs. The tangent shear modulus during the first cycle is expressed as

$G_{t}=\frac{G_{\max }}{\left[1+\left(G_{\max } / \tau_{\max _{o c t}}\right)\left|\gamma_{\varepsilon_{o c t}}\right|\right]^{2}}$

where $G_{\max }$ is the initial shear modulus, $\tau_{\max _{o c t}}$ is the maximum octahedral shear stress in 3D states which is related to shear parameters of soil through cohesion $c$ and internal angle of friction $\phi$, and $\tau_{\text {max }_{o c t}}$ is the octahedral shear strain. The tangent modulus during unloading/ reloading cycle is
$G_{t}=\frac{G_{\max }}{\left[1+\left(G_{\max } / 2 \tau_{\max _{o c t}}\right) \mid \Delta \gamma_{o c t}\right]^{2}}$

where $\Delta \gamma_{o c t}$ represents the difference in octahedral shear strain during unloading/reloading cycle. In unloading case as it equals to $\gamma_{\varepsilon_{o c t}}-\gamma_{u_{o c t}}$ and in reloading case it is $\gamma_{\varepsilon_{o c t}}-\gamma_{r_{o c t}} \cdot \gamma_{\varepsilon_{o c t}}$ is the octahedral shear strain at present state and $\gamma_{u_{o c t}}$ and $\gamma_{r_{o c t}}$ are octahedral shear strains at starting points of unloading and reloading, respectively, for that cycle. The tangent bulk modulus $B_{t}$ is expressed in the following form:

$B_{t}=K_{b} \times p_{a} \times\left(\frac{\sigma_{m}}{p_{a}}\right)^{n}$

in which $K_{b}$ is the bulk modulus constant and $n$ is the bulk modulus exponent.

Damping in the form of local damping ratio of $5 \%$ is adopted for soil elements during dynamic analysis to simulate the damping of soil at low strain levels. Liu et al. [34] also considered similar non-linear cyclic hysteretic behavior of soil along with damping value for the analysis of seismic behavior of geosynthetic reinforced soil walls.

\section{Reinforcement Material (Geotextile)}

The geotextile reinforcement is modeled using the geogrid structural element available in FLAC ${ }^{3 \mathrm{D}}$. The geogrid elements are three nodded shell elements used to model flexible membrane that resist as membrane but do not resist bending loading. The geogrid element behaves as isotropic linear elastic material with no failure limit. The studies of failure of reinforced soil walls [5-7] revealed that the failure of reinforced soil wall is due to subsidence of facing system and backfill soil. The reinforcement failures rarely observed. So geogrid element without any failure limit can be used in 
numerical simulations. The required input parameters for geogrid element in FLAC $^{3 \mathrm{D}}$ are: mass, stiffness, and thickness of geogrid which are adopted as $0.11 \mathrm{~kg} / \mathrm{m}^{3}, 5.2 \mathrm{kN} / \mathrm{m}$, and $0.001 \mathrm{~m}$, respectively. Hysteretic behavior of geosynthetics material is not considered for simulation because the hysteretic behavior of soil is predominant one. This approach is also adopted by several researchers [24, 26, 27, 30, 32, 35].

\section{Interface Properties}

Two different interfaces are considered in the present model: interface between backfill soil and wall and interface between soil and reinforcement.

The interface between backfill soil and rigid wall controls the relative movement between them. The relative interface movement is controlled by interface normal stiffness $\left(k_{n}\right)$ and shear stiffness $\left(k_{s}\right)$. A recommended thumb rule is that $k_{s}$ and $k_{n}$ be set to ten times the equivalent stiffness of the stiffest neighboring zone. Thus, the maximum stiffness value is determined as [37]:

$k_{n}=k_{s}=10 \times \max \left[\frac{K+\frac{4}{3} G}{(\Delta z)_{\min }}\right]$

where the parameters $(\Delta z)_{\min }, K$ and $G$ are the smallest dimensions in normal direction, bulk modulus and shear modulus of continuum zone adjacent to the interface, respectively. This approach gives the preliminary values of the interface stiffness components, and these can be adjusted to avoid intrusion to adjacent zone and to prevent excessive computation time.

The interface behavior of geogrid is represented numerically at each geogrid node by a rigid attachment in normal direction and spring-slider in the tangent plane to the geogrid surface. The orientation of the spring-slider changes in response to the shear displacement between geogrid and neighboring soil elements. The shear behavior of the geogrid-soil interface is cohesive and frictional in nature and is controlled by coupling spring properties: (1) stiffness per unit area $k$; (2) cohesive strength $c$; (3) friction angle $\phi$ and by effective confining stress $\sigma_{m}$. The effective confining stress $\sigma_{m}$ acts perpendicular to the geogrid surface and computed at each geogrid node [37]. The shear strength of the interfaces between the soils and geosynthetics are determined based on interface friction angle, $\delta=\tan ^{-1}\left(\frac{2}{3} \tan \phi\right)$, [41]. The various material properties used in simulation of the validation model are listed in Table 1.

\section{Development of Numerical Model}

A rigid zone of size $800 \mathrm{~mm}$ long and $50 \mathrm{~mm}$ thick is considered at the base of wall to represent the shaking table. Model grid of $25 \mathrm{~mm}$ wide and $600 \mathrm{~mm}$ high is considered as the rigid wall. The lateral dimension of $100 \mathrm{~mm}$ is considered to observe the model response. The dimension of the physical model is $500 \mathrm{~mm}$, but the $100 \mathrm{~mm}$ lateral dimension is considered for the ease of solving. A grid of $600 \mathrm{~mm}$ high and $750 \mathrm{~mm}$ long is generated to represent the backfill of rigid faced retaining wall. The whole grid is divided in number of zones of size $25 \mathrm{~mm}$ each. Four layers of geotextile reinforcement of length $\left(L_{\text {rein }}\right) 420 \mathrm{~mm}$ are used in the model. Figure 2 shows the numerical grid considered to simulate the rigid faced retaining wall.

Construction sequence with layers of equal thickness is followed in the numerical model generation, similar to that of physical model. The foundation zone is brought to static equilibrium before placing the rigid wall and backfill. The wall is then placed over the foundation zone and brought to static equilibrium. The horizontal movement of wall is restricted to represent temporary supports during the construction. The backfill model is generated in equal lifts. The reinforcement is placed after placing each lift. The reinforcements are extended to the wall and attached with the wall to represent rigid connection between wall and reinforcement. The structural elements in FLAC ${ }^{3 \mathrm{D}}$ interacts with main grid at structural element nodes. But at the interface between wall and soil, the geogrid nodes may arbitrarily select nodes either from wall or from soil. So, finer grid is considered for wall portion so that more structural nodes interact with wall nodes. The model is brought to static equilibrium after each lift. A surcharge of $0.5 \mathrm{kPa}$ is applied at top after all lifts up to full height of wall $(H)$ and model is brought to static equilibrium. The supports of the wall are removed after the end of construction.

\section{Boundary Conditions}

The boundary conditions applied to the numerical model, in such a way that they represent the actual boundary of the physical model tests [21]. The bottom boundaries are completely fixed in vertical direction to represent the rigid boundary between the model wall and shaking table. The far end boundary elements are fixed in the $x$ direction to represent the fixed container during construction. During construction, the model wall is fixed in horizontal direction to represent temporary facing supports. The lateral boundaries are fixed in the $y$ direction to represent the lateral boundaries at the side of the physical model. After all layers construction is completed and the model has been brought to equilibrium, the facing supports are removed stage by stage. After the support removal in each stage, the model is brought to equilibrium. The boundary conditions of the model are shown in Fig. 3. During dynamic run free field boundary is applied to far end to represent the laminar boxes. The dynamic excitation is applied at the stiff bottom 
Table 1 Material properties used in numerical simulation

\begin{tabular}{lll}
\hline & Validation model & Full scale model \\
\hline Wall properties & & \\
Unit weight $\left(\mathrm{kN} / \mathrm{m}^{3)}\right.$ & 2.50 & \\
Elastic modulus $(\mathrm{kPa})$ & $2 \times 10^{7}$ & \\
Soil properties for Mohr model & & \\
Mass density $\left(\mathrm{kg} / \mathrm{m}^{3)}\right.$ & 1630 & \\
Elastic modulus $(\mathrm{kPa})$ & $1 \times 10^{4}$ & $38^{\circ}$ \\
Poisson's ratio & 0.3 & \\
Friction angle & $43^{\circ}$ & \\
Dilation angle & $15^{\circ}$ & 0.23 \\
Cohesion $(\mathrm{kPa})$ & 0.1 & 0.001 \\
Reinforcement $(\mathrm{geotextile})$ properties & & 152 \\
Mass density $\left(\mathrm{kg} / \mathrm{m}^{3)}\right.$ & 0.11 & \\
Thickness $(\mathrm{m})$ & 0.001 & \\
Stiffness $(\mathrm{kN} / \mathrm{m})$ & 5.2 & \\
Reinforcement $(\mathrm{geotextile})$ interface properties & & \\
Coupling spring cohesion $(\mathrm{kPa})$ & 0.1 & $29^{\circ}$ \\
Coupling spring friction angle & $1 \times 10^{6}$ & \\
Coupling spring stiffness $(\mathrm{kPa})$ & & \\
\hline
\end{tabular}

Fig. 2 Grid adopted for numerical simulation

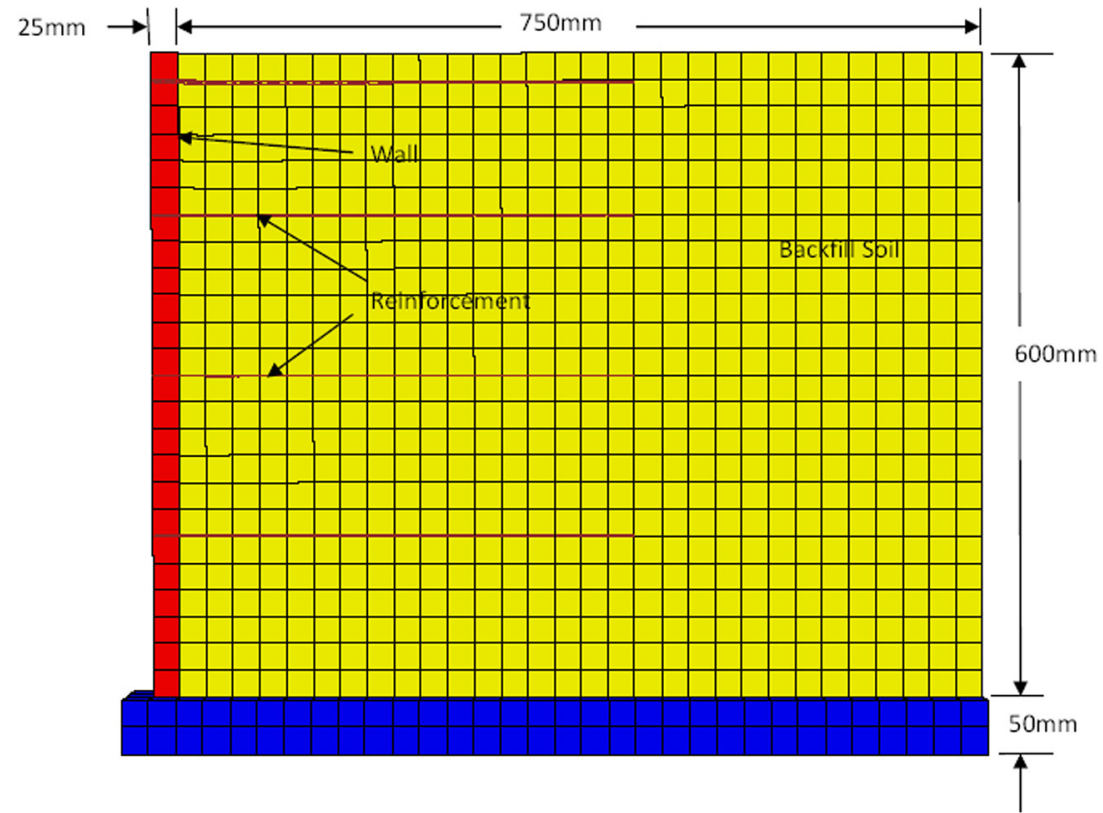

in the form of wave velocity in horizontal direction (uniaxial shaking).

\section{Typical Results and Validation}

Unreinforced and reinforced retaining wall models were tested for validation with sinusoidal dynamic excitation of $0.2 \mathrm{~g}$ base acceleration (a) at $3 \mathrm{~Hz}$ frequency for 20 cycles. The frequencies $2-3 \mathrm{~Hz}$ are represent predominant frequency of medium to high frequency earthquakes [26, 42] and also within earthquake parameters for seismic design [43]. Results are analyzed in terms of displacement, accelerations and pressures. Typical variations of displacements and accelerations with number of dynamic loading cycles at different elevations within the backfill soil of reinforced soil wall are shown in Figs. 4 and 5, respectively. The horizontal displacements increase nonlinearly with increase in number of cycles. The horizontal displacement of wall is greater at higher elevations of wall. 
Fig. 3 Boundary conditions of the model in $\mathrm{X}-\mathrm{Y}$ plane and $\mathrm{Z}-$ $\mathrm{X}$ plane
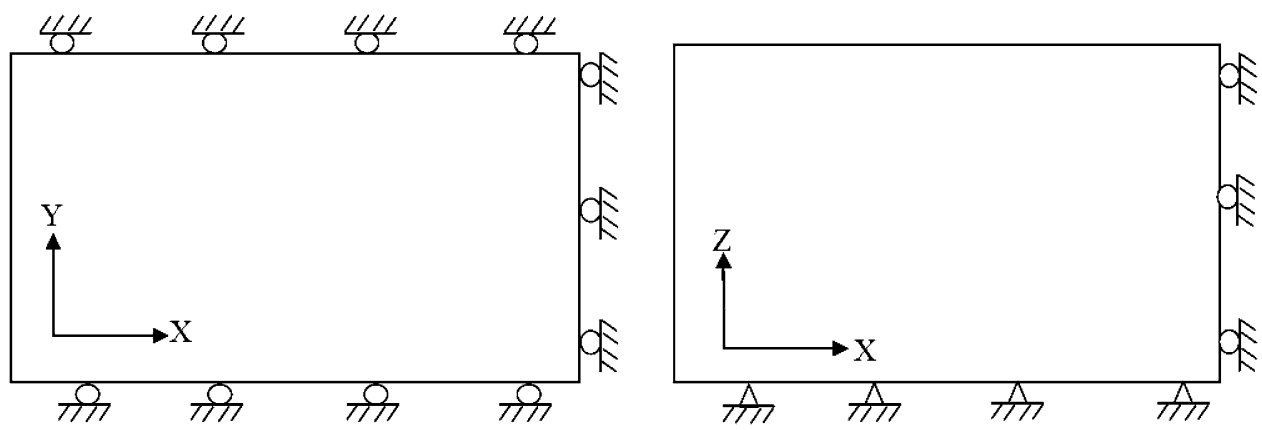

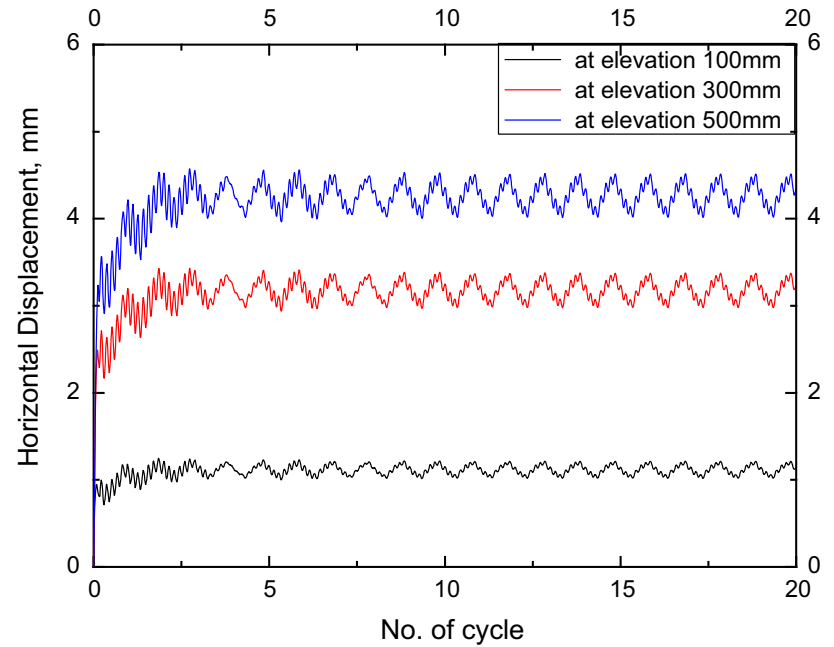

Fig. 4 Typical displacement histories at different elevation for $a=0.2 \mathrm{~g}$ and $f=3 \mathrm{~Hz}$

The accelerations are amplified at higher elevations of wall.

The acceleration amplifications at different elevation of wall are quantified as root mean square acceleration (RMSA) amplification factor. RMSA amplification factor is the ratio of RMS acceleration values at different elevation to that of base RMS acceleration value. The RMS acceleration value are calculated according to Eq. 6 [44].

$\mathrm{RMS}=\left[\frac{1}{t_{d}} \int_{0}^{t_{d}} a(t)^{2} d t\right]^{1 / 2}$

where $a(t)$ is acceleration at time $t, t_{d}$ is the duration of the acceleration record and $d t$ is time interval of the acceleration record.

Figure 6 compares the variation of horizontal displacements, RMSA amplification factors and horizontal pressure increments at different elevations obtained from physical and numerical models of reinforced and unreinforced walls. The incremental pressure is the measured increase in lateral pressure during dynamic excitation on the back of the facing. The maximum horizontal displacement of unreinforced wall at an elevation of $500 \mathrm{~mm}$ is $12.8 \mathrm{~mm}$ for numerical model and that of physical model is $11.0 \mathrm{~mm}$. The maximum horizontal displacement for reinforced wall at an elevation of $500 \mathrm{~mm}$ is $4.3 \mathrm{~mm}$ for numerical model and that of physical model is $4.0 \mathrm{~mm}$. The acceleration amplification of unreinforced wall at an elevation of $600 \mathrm{~mm}$ is 1.25 for numerical model and that of physical model is 1.21 . The corresponding values for reinforced wall are 1.09 for numerical model and 1.14 for physical model. The incremental pressure for unreinforced wall at an elevation of $100 \mathrm{~mm}$ is $0.19 \mathrm{kPa}$ for numerical model and $0.06 \mathrm{kPa}$ for physical model. While incremental pressure for reinforced wall is $0.33 \mathrm{kPa}$ for numerical model and $0.23 \mathrm{kPa}$ for physical model. Krishna and Latha [21] reported that the incremental pressure measurements were inconsistent owing to the issues related to pressure sensor sensing range $(0-100 \mathrm{kPa})$ in relation to the range pressures encountered during testing $(<3 \mathrm{kPa})$. So discrepancies in the incremental pressures are observed between the experimental and simulated results. The results obtained show the ability of the numerical model to capture the behavior of the physical model and confirms the validation of the model developed.

Variations of octahedral shear stains, horizontal and vertical displacements along the length of backfill are analyzed for unreinforced and reinforced $\left(N_{L}=4\right)$ wall models, subjected to dynamic excitation $(a=0.2 \mathrm{~g}$; $f=3 \mathrm{~Hz}$ ), are being observed. The octahedral strain states are calculated from six strains acting on each element. The octahedral strain invariants are strain parameters independent of the choice of reference axis [45] and are expressed as

$$
\begin{aligned}
\gamma_{o c t} & =\frac{2}{3}\left[\left(\varepsilon_{x x}-\varepsilon_{y y}\right)^{2}+\left(\varepsilon_{y y}-\varepsilon_{z z}\right)^{2}+\left(\varepsilon_{z z}-\varepsilon_{x x}\right)^{2}\right. \\
& \left.+6\left(\varepsilon_{x y}^{2}+\varepsilon_{y z}^{2}+\varepsilon_{z x}^{2}\right)\right]^{1 / 2}
\end{aligned}
$$

where $\varepsilon_{x x}, \varepsilon_{y y}, \varepsilon_{z z}, \varepsilon_{x y}, \varepsilon_{y z}$ and $\varepsilon_{z x}$ are strain parameters acting on each element in three dimensional state.

Figure 7 shows the shear strain, and displacements variations for unreinforced soil wall. In general, the maximum 
Fig. 5 Typical acceleration histories obtained in numerical simulation
Fig. 6 Comparison of results from numerical and physical model tests on unreinforced and reinforced ( $a=0.2 \mathrm{~g}, f=3 \mathrm{~Hz}$ and $\left.N_{L}=4\right)$ : a displacement profiles; $\mathbf{b}$ acceleration amplification and $\mathbf{c}$ incremental pressure

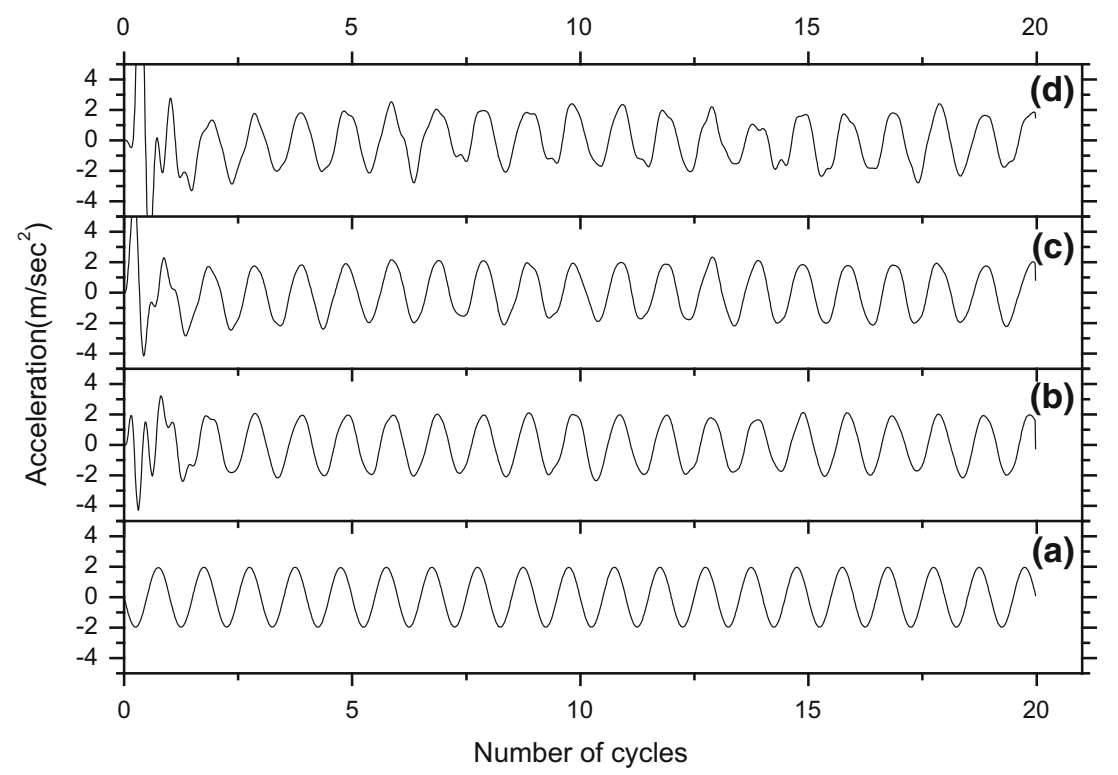

values of horizontal displacement $(u)$ and vertical displacements $(v)$ and incremental octahedral shear strain $\left(\Delta \gamma_{\text {oct }}\right)$ are observed near the wall facing and they decrease gradually along the length of the backfill. Maximum horizontal displacements are 11.0, 9.0, 4.1 and $0.6 \mathrm{~mm}$, at 525, 375, 225 and $75 \mathrm{~mm}$ elevations, respectively. The corresponding maximum vertical displacements $(v)$ are in the range of $5.52-0.5 \mathrm{~mm}$. The $\Delta \gamma_{o c t}$ are $10.8 \%$ near the wall facing at $525 \mathrm{~mm}$ elevation and in the order of $4 \%$ at other elevations. Figure 8 shows the similar results for a reinforced soil wall with four layers of reinforcement. The maximum $u$ at $525 \mathrm{~mm}$ elevation is $4.0 \mathrm{~mm}$ near the wall face and it remains same up to the end of reinforcement (up to $420 \mathrm{~mm}$ length). From this point onwards a slight decrease in the $u$, up to the end of wall, is observed. Almost similar behavior has been observed at the other elevations also. The vertical displacements $(v)$ are very low and almost uniform except, near the end of reinforcement, along the length of backfill at different elevations. The $\Delta \gamma_{\text {oct }}$ are less than $0.75 \%$ within reinforced zone but increase to $1.0 \%$ at the end of 
Fig. $7 \Delta \gamma_{o c t}, u$ and $v$ along length of backfill after dynamic excitation $(a=0.2 \mathrm{~g}$ and $f=3 \mathrm{~Hz}$ ) for unreinforced wall
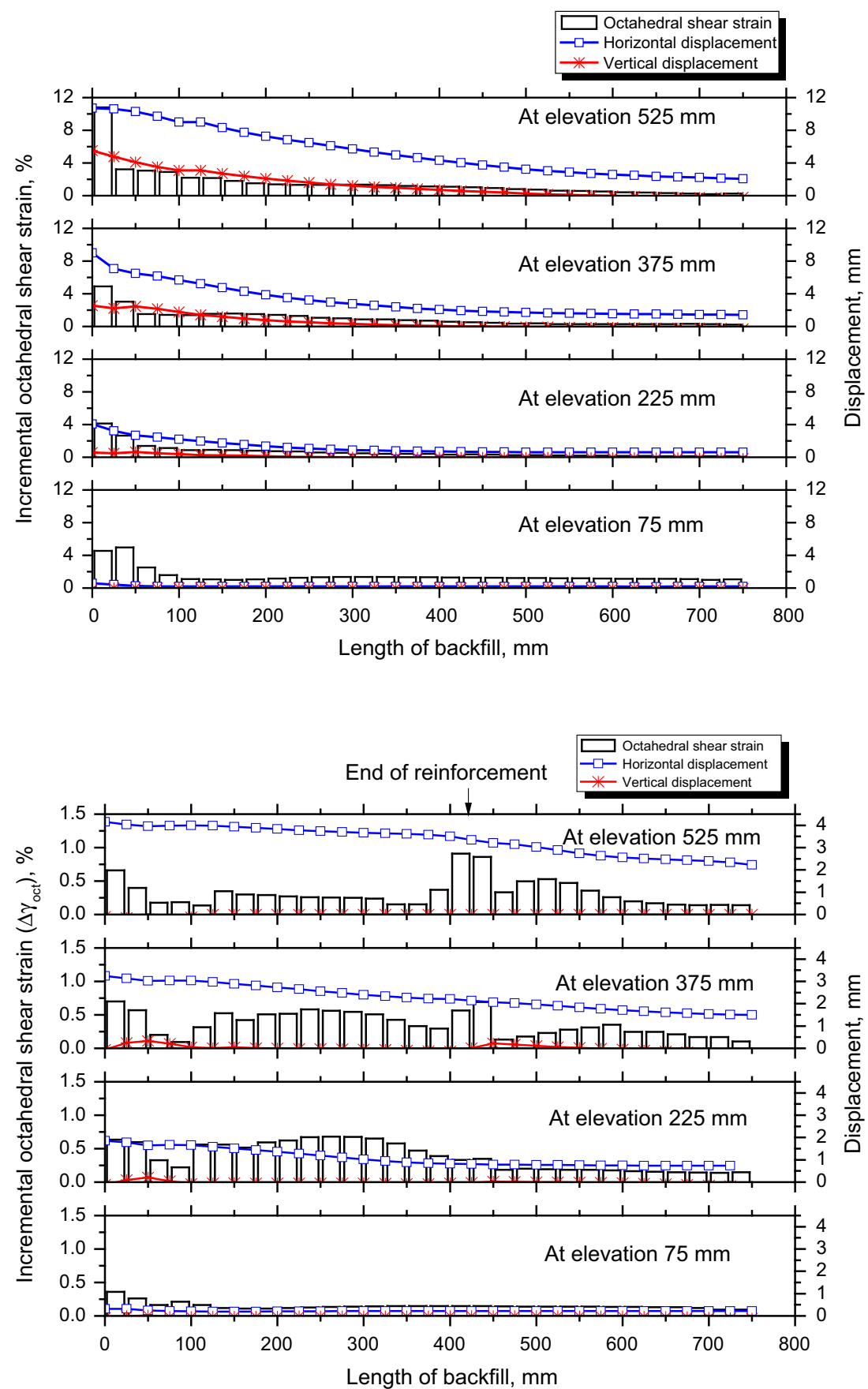

Fig. $8 \Delta \gamma_{o c t}, u$ and $v$ along length of backfill of dynamic excitation for reinforced wall ( $a=0.2 \mathrm{~g}$ and $f=3 \mathrm{~Hz}, L_{\text {rein }} /$ $H=0.7$ and $\left.N_{L}=4\right)$ reinforcement. Comparisons of unreinforced and reinforced wall responses show significant reductions in $\Delta \gamma_{o c t}, u$, and $v$ values. Backfill soil, near the facing is subjected to more strains in unreinforced wall and decreases gradually, while the maximum strains are near the end of reinforcement for reinforced retaining wall. These observations indicate that, the whole reinforced zone acts together as rigid body in case of reinforced retaining wall. The horizontal displacements are not reduced to minimum value near the far end boundary of wall. The model response is affected by far end boundary for both unreinforced and reinforced retaining wall and also reported in literature [21].

\section{Response of Full Scale Reinforced Soil Retaining Wall under Seismic Excitation}

Seismic behavior of a full scale rigid-faced model of $6 \mathrm{~m}$ high $(H), 18 \mathrm{~m}$ long and $1 \mathrm{~m}$ wide with four reinforcement layers is studied, using the validated numerical model. The 
model parameters are kept same as that of laboratory model, except the reinforcement parameters. A $1 \mathrm{~mm}$ thick geotextile having mass per unit area of $230 \mathrm{~g} / \mathrm{m}^{2}$ with,

Table 2 Static and dynamic factors of safety for full scale rigidfaced model

\begin{tabular}{lllllll}
\hline \multirow{2}{*}{ Loading condition } & \multicolumn{2}{l}{ External stability } & & \multicolumn{2}{c}{ Internal stability } \\
\cline { 3 - 3 } & & $\mathrm{FS}_{\text {basesliding }}$ & $\mathrm{FS}_{\text {overturning }}$ & & $\mathrm{FS}_{\text {rupture }}$ & $\mathrm{FS}_{\text {pullout }}$ \\
\hline Static & 4.16 & 5.34 & & 2.00 & 4.34 \\
Dynamic & $0.2 \mathrm{~g}$ & 1.80 & 1.79 & & 1.97 & 1.95 \\
\hline
\end{tabular}

about $152 \mathrm{kN} / \mathrm{m}$ stiffness is adopted. The length of geotextile reinforcement $\left(L_{\text {rein }}\right)$ is $4.2 \mathrm{~m}$ as per FHWA [46]. The base of wall is fixed against rotation and sliding. A surcharge of $5 \mathrm{kPa}$, resembling $20 \mathrm{~cm}$ thick cement concrete slab, is applied at the top of backfill. The foundation of wall is considered to be rigid hence, vertical displacements are restricted. Stability analysis has been carried out for full scale rigid-faced wall according to FHWA [46]. The factors of safety obtained for static and dynamic stability analyses are tabulated in Table 2 . The safety factors shown in Table 2 indicate that the wall considered is safe against external and internal stability.
Fig. 9 Horizontal, vertical displacements, RMSA amplification factor and horizontal pressure at different elevations after dynamic excitation $(a=0.2 \mathrm{~g}, f=5 \mathrm{~Hz}$ $L_{\text {rein }} / H=0.7, N_{L}=4$ )

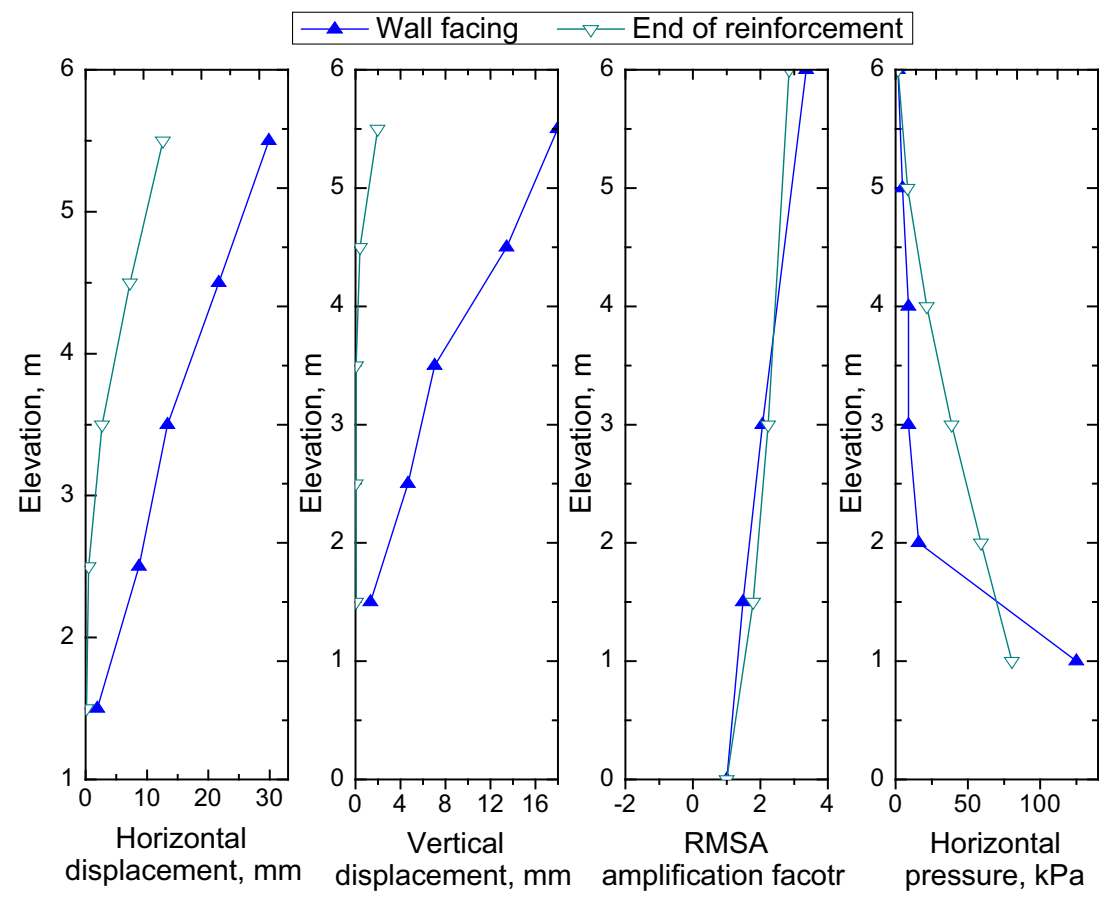

Fig. $10 \Delta \gamma_{\text {oct }}, u$ and $v$ along the length of backfill after 20 cycles of dynamic excitation $\left(a=0.2 \mathrm{~g}, \mathrm{f}=5 \mathrm{~Hz}, L_{\text {rein }} /\right.$ $\left.H=0.7, N_{L}=4\right)$

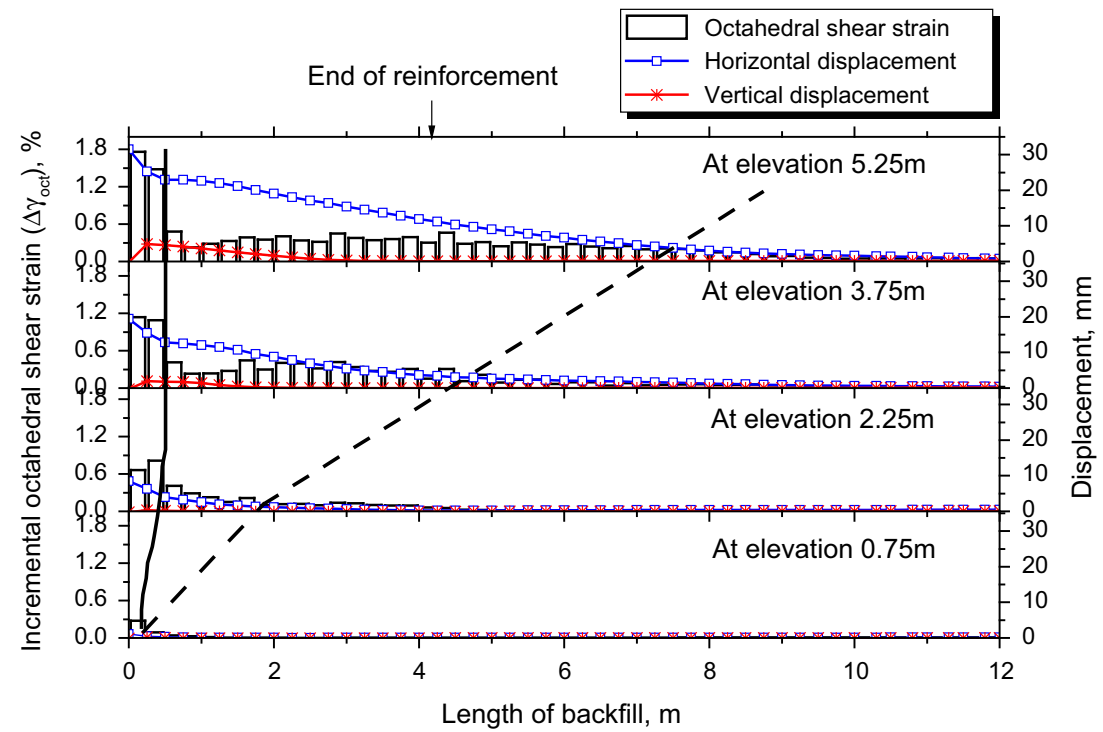


The full scale rigid-faced wall model is subjected to 20 cycles of sinusoidal dynamic excitation of $0.2 \mathrm{~g}$ acceleration $(a)$ at $5 \mathrm{~Hz}$ frequency $(f)$. The fundamental frequency of the rigid wall system is calculated based on model proposed by $\mathrm{Wu}$ [47] and found to be $7.07 \mathrm{~Hz}$. Though $5 \mathrm{~Hz}$ frequency is higher than frequency range of medium to high frequency earthquake but nearer to the fundamental frequency of the rigid face wall model considered. The response of model, after dynamic excitation, is shown in Fig. 9 in the form of horizontal displacements $(u)$, vertical displacements $(v)$, RMSA amplification factors and horizontal pressures, near the facing and at the end of reinforcement. The maximum $u$ are 30.1 and $12.6 \mathrm{~mm}$ near the facing and at the end of reinforcement; and corresponding $v$ are 16.2 and $0.97 \mathrm{~mm}$, respectively. The RMSA amplification factors are 3.36 and 2.85 at wall facing and at the end of reinforcement respectively. The horizontal pressure variation near end of reinforcement follows typical earth pressure distribution.

The incremental octahedral shear strains $\left(\Delta \gamma_{o c t}\right), u$ and $v$ displacements along the length of backfill between two reinforcement layers are presented in Fig. 10. The $\Delta \gamma_{\text {oct }}$ are 1.76 and $1.14 \%$ near the wall facing (confined to zone up to $0.4 \mathrm{~m}$ from facing) at elevation of 5.25 and $3.75 \mathrm{~m}$ respectively. The $\Delta \gamma_{o c t}$ at other part of backfill gradually goes down to $0.3 \%$ at a distance of 5.3 and $2.7 \mathrm{~m}$ at elevation of 5.25 and $3.75 \mathrm{~m}$, respectively. The $u$ near the facing are 29.5 and $19.45 \mathrm{~mm}$ at elevations of 5.25 and $3.75 \mathrm{~m}$, respectively. The $u$ decrease gradually and become less than $10 \mathrm{~mm}$, after the end of reinforcements. The $v$ near the facing are 11.2 and $4.90 \mathrm{~mm}$ at an elevation of 5.25 and $3.75 \mathrm{~m}$ respectively. The $v$ also decreases gradually and less than $1 \mathrm{~mm}$ within the reinforced zone. By observing the variations of $\Delta \gamma_{o c t}, u$ and $v$, two deformation zones are identified. The first zone (solid line in Fig. 10) exists totally in reinforced zone and very close to the facing which can be considered as high strain zone and shows relative settlement of reinforced zone near wall facing. The second zone (dashed line in Fig. 10) is the constant strain zone which is extending beyond reinforced zone, formed due to shear deformation within reinforced zone at higher elevation. This type of deformation zones are also observed by El-Emam and Bathurst [15] and Ling et al. [42] as surface deformations near the wall facing and some tension cracks in backfill.

\section{Effect of Backfill Friction Angle}

The rigid-faced wall models with three different backfill friction angles of $30^{\circ}, 38^{\circ}$ and $43^{\circ}$ are considered. The comparative results after seismic excitation $(a=0.2 \mathrm{~g}$, $f=5 \mathrm{~Hz}$ ) are shown in Fig. 11a. The maximum horizontal and vertical displacements of 38.44 and $18.59 \mathrm{~mm}$
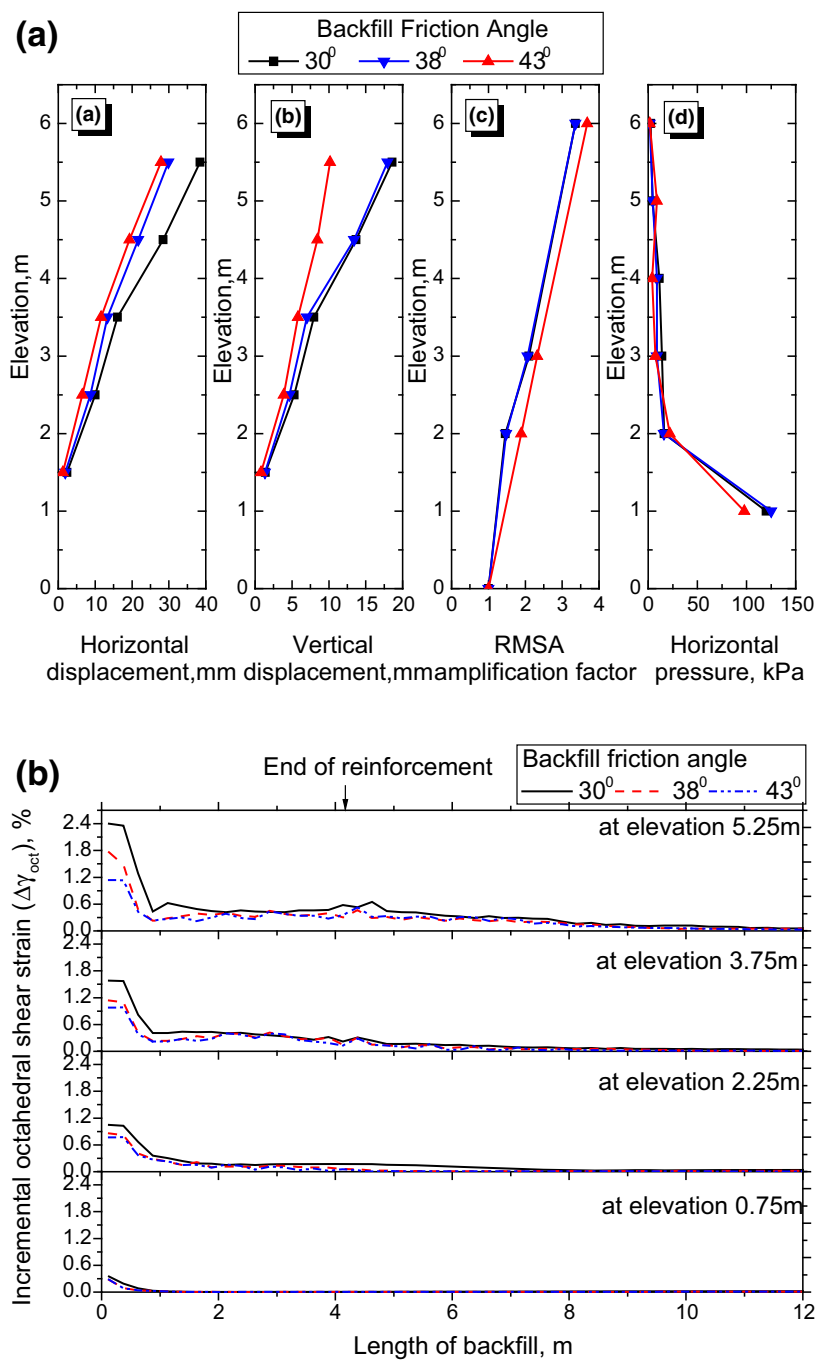

Fig. 11 a Response of model walls with backfill friction angles $30^{\circ}$, $38^{\circ}$ and $43^{\circ}$ subjected to dynamic excitation ( $a=0.2 \mathrm{~g}, f=5 \mathrm{~Hz}$ and $\left.L_{\text {rein }} / H=0.7, N_{L}=4\right)$. b Comparison of $\Delta \gamma_{o c t}$ at backfill for wall with backfill friction angle $30^{\circ}, 38^{\circ}$ and $43^{\circ}$ after dynamic excitation ( $a=0.2 \mathrm{~g}, f=5 \mathrm{~Hz}$ and $L_{\text {rein }} / H=0.7, N_{L}=4$ )

observed near facing at elevation $5.5 \mathrm{~m}$ for wall with backfill friction angle $30^{\circ}$. About 27 and $45 \%$ reduction in horizontal and vertical displacements near the facing are observed for change in backfill friction angle to $43^{\circ}$. The RMSA amplification factors at top are 3.36 and 3.38 for wall with backfill friction angle $38^{\circ}$ and $43^{\circ}$. The horizontal pressures do not have any appreciable variation for wall with different backfill friction angles. Comparison of incremental octahedral shear strain $\left(\Delta \gamma_{o c t}\right)$ developed within soil elements after dynamic excitation for wall with different backfill friction angles is shown in Fig. 11b. The $\Delta \gamma_{\text {oct }}$ near the wall facing at elevation $5.25 \mathrm{~m}$ are $2.4,1.76$ and $1.14 \%$ for wall with backfill friction angles of $30^{\circ}, 38^{\circ}$ and $43^{\circ}$, respectively. The $\Delta \gamma_{o c t}$ are within the range of $0.7-0.3 \%$ in reinforced zone and decreases to negligible 
Fig. 12 Comparison of $\Delta \gamma_{o c t}$ at backfill for wall with reinforcement stiffness 5.2, 100 and $152 \mathrm{kN} / \mathrm{m}$ after dynamic excitation $(a=0.2 \mathrm{~g}, f=5 \mathrm{~Hz}$ and $L_{\text {rein }} / H=0.7, N_{L}=4$ )

Fig. 13 Comparison of $\Delta \gamma_{o c t}$ at backfill for wall with $L_{\text {rein }} / H=$ $0.7,1.0$ and 1.2 after dynamic excitation $(a=0.2 \mathrm{~g}, f=5 \mathrm{~Hz}$ and $\left.N_{L}=4\right)$
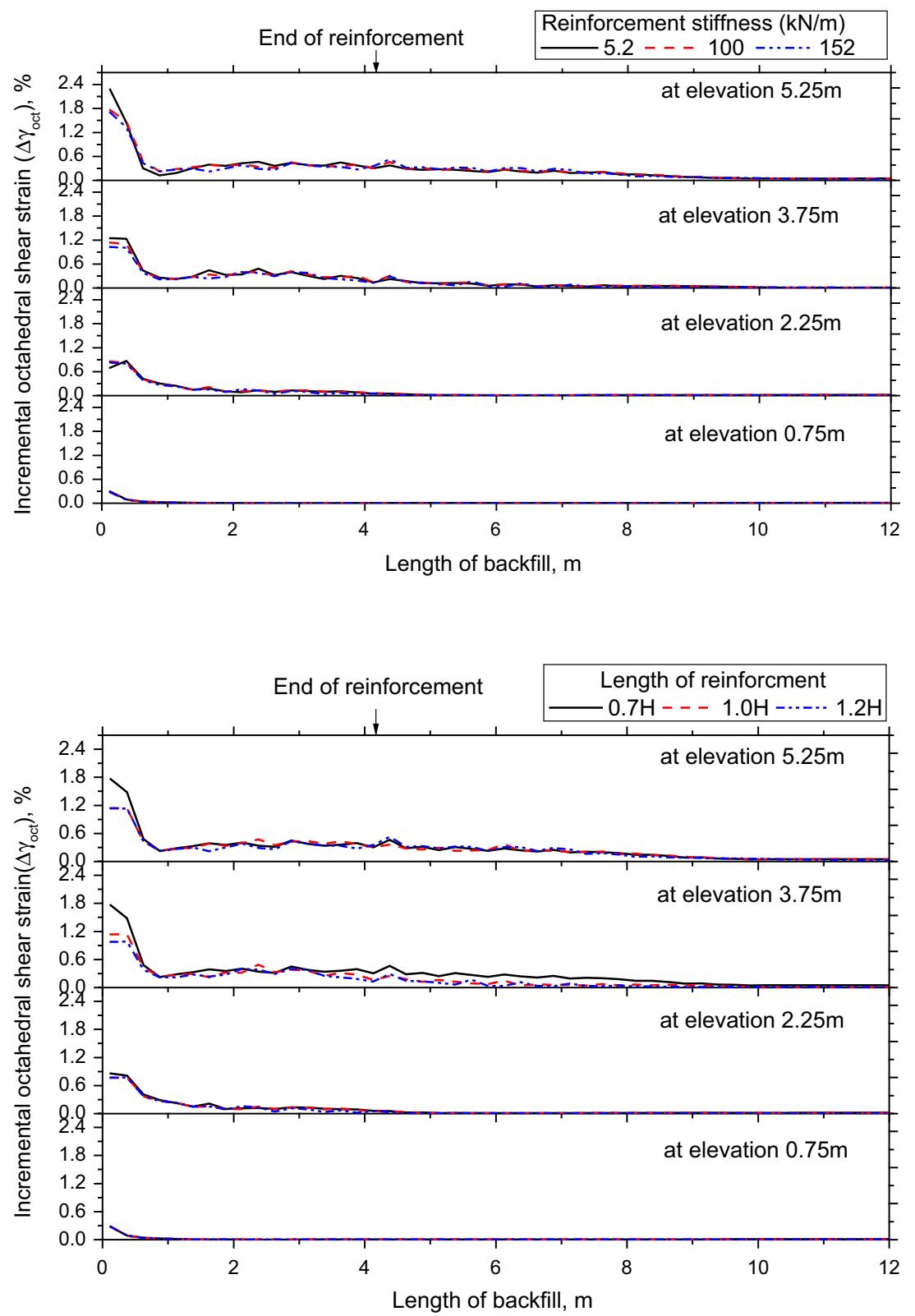

value at $8 \mathrm{~m}$ from facing. The increase in vertical settlements $(v)$ near the wall facing causes higher strain near facing for three different backfill soils.

\section{Effect of Reinforcement Stiffness}

Comparison of $\Delta \gamma_{o c t}$ in backfill soil for wall with different reinforcement stiffness of 5.2, 100 and $152 \mathrm{kN} / \mathrm{m}$ is shown in Fig. 12. The $\Delta \gamma_{\text {oct }}$ near the wall facing at elevation $5.25 \mathrm{~m}$ are $2.7,1.76$ and $1.7 \%$ for wall with reinforcement stiffness 5.2, 100 and $152 \mathrm{kN} / \mathrm{m}$, respectively. At other elevations, almost same strain increments near the wall facing are observed for model walls with different reinforcement stiffness. The $\Delta \gamma_{o c t}$ values did not affected much with reinforcement stiffness. A high strained zone showing relative settlement is formed near the facing for three model walls.

\section{Effect of Length of Reinforcing Layers}

Three different reinforcement lengths $\left(L_{\text {rein }}\right) \quad 0.7 \mathrm{H}$, $1.0 H$ and $1.2 H$ ( $H$ is the height of wall) are considered. Comparison of $\Delta \gamma_{\text {oct }}$ in backfill soil for three different reinforcement lengths $\left(L_{\text {rein }}=0.7 \mathrm{H}, 1.0 \mathrm{H}\right.$ and $\left.1.2 \mathrm{H}\right)$ is shown in Fig. 13. The $\Delta \gamma_{o c t}$ near the facing is 1.76 and $1.14 \%$ for reinforcement length of $0.7 \mathrm{H}$ and $1.0 \mathrm{H}$ respectively. The strain variation in soil for wall with reinforcement length $1.0 \mathrm{H}$ and $1.2 \mathrm{H}$ are almost same. Comparisons 
Fig. 14 Comparison of $\Delta \gamma_{\text {oct }}$ at backfill for wall with four, six and eight layers of reinforcement after dynamic excitation $(a=0.2 \mathrm{~g}, f=5 \mathrm{~Hz}$ and $\left.L_{\text {rein }} / H=0.7\right)$
Fig. 15 Comparison of $\Delta \gamma_{\text {oct }}$ at backfill for wall with facing stiffness $27.4 \mathrm{GPa}$ and $15.2 \mathrm{GPa}$ after dynamic excitation ( $a=0.2 \mathrm{~g}, f=5 \mathrm{~Hz}$ and $L_{\text {rein }} /$ $H=0.7)$
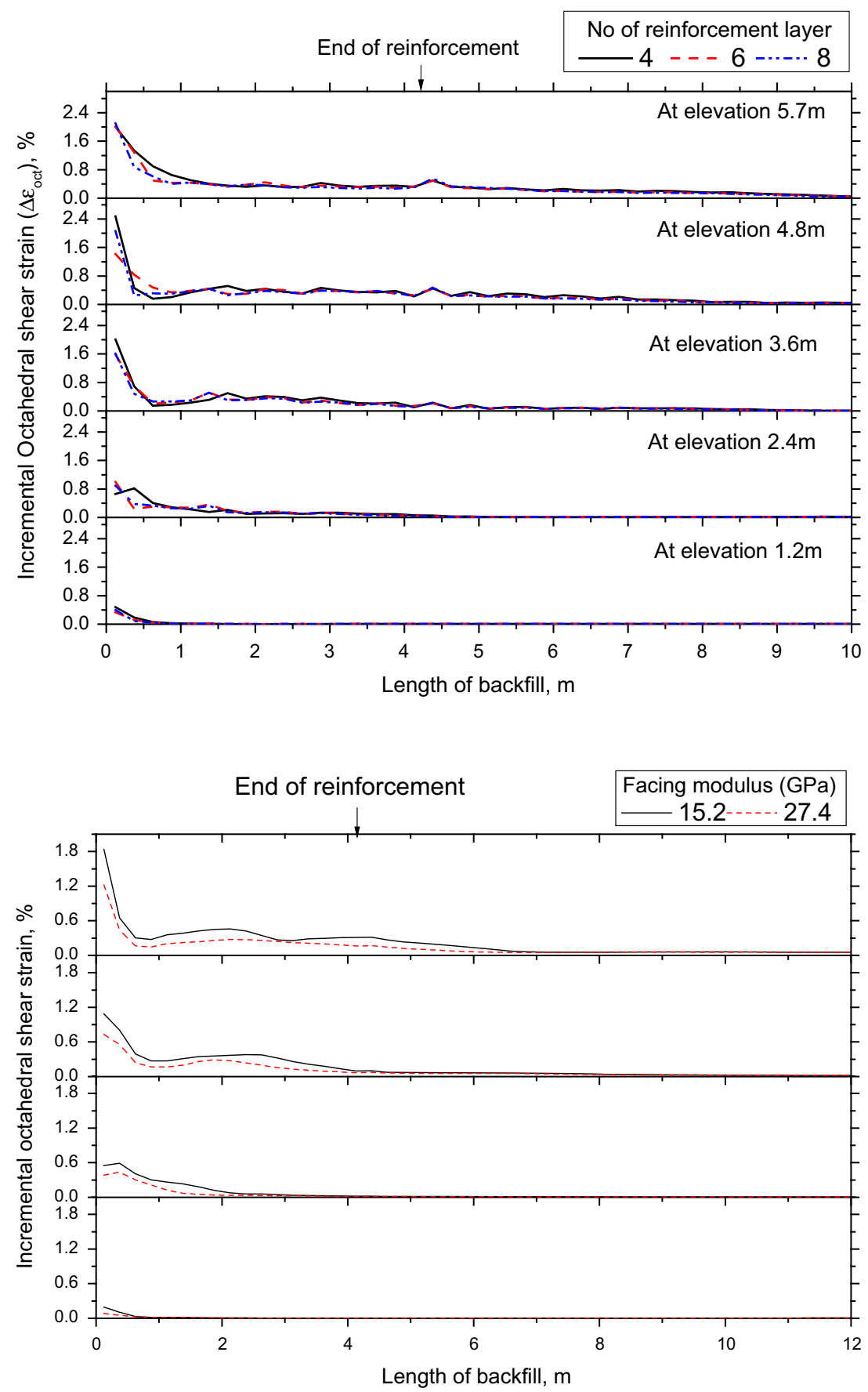

of strain in soil depict more vertical settlement near the facing for wall with reinforcement length $0.7 \mathrm{H}$.

\section{Effect of Number of Reinforcing Layers}

The rigid-faced wall with four, six and eight numbers of reinforcing layers subjected to 20 cycles of dynamic excitation of $0.2 \mathrm{~g}$ and frequency $5 \mathrm{~Hz}$ are considered. The $\Delta \gamma_{\text {oct }}$ in backfill soil are compared for walls with four, six and eight layers of reinforcement in Fig. 14. Common elevations, which are not at reinforcement levels, are considered for determination of $\Delta \gamma_{o c t}$. The maximum $\Delta \gamma_{o c t}$ is near the wall and is almost remain constant after $0.4 \mathrm{~m}$ from facing within reinforced zone, then decrease to negligible value at a distance of $8 \mathrm{~m}$ from facing at higher elevation for wall with four, six and eight layers of reinforcement. The maximum incremental shear strain at elevations $5.7 \mathrm{~m}$ is $2.52 \%$ for wall with four layers of reinforcement and $2.15 \%$ and $2.08 \%$ for wall with six and eight layers of reinforcement. The variation of octahedral shear strain along backfill shows a zone of 
relative settlement near the facing and shear deformation within reinforced zone for wall with four, six and eight layers of reinforcement.

\section{Effect of Facing Stiffness}

Rigid-faced wall with different facing modulus of 27.4 and 15.2 GPa, resembling M30 and M10 grade concrete, are considered for analysis. Figure 15 shows comparison of $\Delta \gamma_{o c t}$ between two reinforcement layers after dynamic excitation. The variation of octahedral shear strain along backfill shows a zone of relative settlement near the facing and shear deformation within reinforced zone for wall with facing modulus 15.2 and 27.4 GPa. The variation of octahedral shear strain along backfill shows more relative settlement near the facing for wall with lesser facing stiffness. So the facing stiffness also one parameters to be considered for design of reinforced soil walls.

\section{Conclusions}

The numerical model developed for laboratory scale rigidfaced walls is reasonably good in simulating dynamic responses and sensitive to the different material properties. In laboratory scale models, maximum shear strain developed was about $12 \%$ near the facing for unreinforced wall, while it is about $1 \%$, near the end of reinforcement for reinforced wall. Displacements were significantly reduced by about $50-75 \%$ by reinforcing layers.

Studies on full scale rigid-faced reinforced wall models showed two types of strained zones: high strain zone near the wall facing; and low strained zone extending into the retained backfill. Larger localised vertical and horizontal displacements near the wall facing indicate high strain zone (about 1-2 \%); Low strain zone was marked by the extent of the retained backfill experiencing elastic strain level (around $0.3 \%$ ). The variation of length and stiffness of reinforcement, number of reinforcement layers; and backfill soil could marginally effect the strained zones, other than small changes near the wall facing at acceleration of $0.2 \mathrm{~g}$.

The facing stiffness affects the response of the rigidfaced wall. The horizontal displacement of wall and vertical displacement of the backfill increases with decrease in wall stiffness. The strain increments in soil are higher for model with lesser wall stiffness.

\section{References}

1. Holtz RD (2001) Geosynthetics for soil reinforcement. Ninth Spencer J. Buchanan Lecture, College Station, Texas, November 9, 2001, p 20
2. Sakaguchi M (1996) A study of the seismic behaviour of geosynthetic reinforced walls in Japan. Geosynth Int 3(1):13-30

3. Tatsuoka F, Tateyama M, Uchimura T, Koseki J (1997) Geosynthetic reinforced soil retaining walls as important permanent structures. Geosynth Int 4(2):81-136

4. Koseki J, Bathurst RJ, Güler E, Kuwano J, Maugeri M (2006) Seismic stability of reinforced soil walls. Proceedings of the 8th international conference on geosynthetics, pp 51-78

5. Ling HI, Leshchinsky D, Chou NNS (2001) Post-earthquake investigation on several geosynthetics-reinforced soil retaining walls and slopes during Ji-Ji earthquake of Taiwan. Soil Dyn Earthq Eng 21:297-313

6. Pamuk A, Ling HI, Leshchinsky D, Kalkan E, Adalier K(2004) Behavior of reinforced wall system during the 1999 Kocaeli (Izmit), Turkey, Earthquake, Proceedings of 5th international conference on case histories in geotechnical engineering, New York

7. Ling HI, Leshchinsky D (2005) Failure analysis of modular-block reinforced-soil walls during earthquake. J Perform Constr Facil ASCE 19(2):117-123

8. Bathurst RJ, Cai Z (1995) Pseudo-static seismic analysis of geosynthetic-reinforced segmental retaining wall. Geosynth Int 2(5):787-830

9. Ling HI (2001) Recent applications of sliding block theory to geotechnical design. Soil Dyn Earthq Eng 21:189-197

10. Huang CC, Chou LH, Tatsuoka F (2003) Seismic displacements of geosynthetic-reinforced soil modular block walls. Geosynth Int 10(1):2-23

11. Nimbalkar SS, Choudhury D, Mandal JN (2006) Seismic stability of reinforced-soil wall by pseudo-dynamic method. Geosynth Int 13(3):111-119

12. Nouri H, Fakher A, Jones CJFP (2008) Evaluating the effects of the magnitude and amplification of pseudo-static acceleration on reinforced soil slopes and walls using the limit equilibrium horizontal slices method. Geotext Geomembr 26:263-278

13. Reddy GVN, Madhav MR, Reddy ES (2008) Pseudo-static seismic analysis of reinforced soil wall- effect of oblique displacement 26:393-408

14. Basha BM, Babu GLS (2009) Seismic reliability assessment of external stability of reinforced soil wall using pseudo-dynamic method. Geosynth Int 16(3):199-215

15. Ramakrishnan K, Budhu M, Britto A (1998) Laboratory seismic tests on geotextile wrap-faced and geotextile-reinforced segmental retaining walls. Geosynth Int 5(1-2):55-71

16. Ling HI, Mohri Y, Leshchinsky D, Burke C, Matsushima K, Liu $\mathrm{H}$ (2005) Large scale shaking table tests on modular-block reinforced soil retaining walls. J Geotech Geoenviron Eng (ASCE) 131(4):465-476

17. Nova-Roessig L, Sitar N (2006) Centrifuge model studies of the seismic response of reinforced soil slopes. J Geotech Geoenviron Eng 132(3):388-400

18. El-Emam MM, Bathurst RJ, Hatami K(2004) Numerical modeling of reinforced soil retaining walls subjected to base acceleration. Proceedings of $13^{\text {th }}$ world conference on earthquake engineering, Vancouver, B.C., Canada, paper no. 2621

19. El-Emam MM, Bathurst RJ (2005) Facing contribution to seismic response of reduced-scale reinforced soil walls. Geosynth Int 12(3):215-238

20. El-Emam MM, Bathurst RJ (2007) Influence of reinforcement parameters on the seismic response of reduced-scale reinforced soil retaining walls. Geotext Geomembr 25(1):33-49

21. Krishna AM, Latha GM (2009) Seismic behavior of rigid-faced reinforced soil retaining wall models: reinforcement effect. Geosynth Int 16(5):364-371

22. Sabermahandi M, Ghalandarzadeh A, Fakher A (2009) Experimental study on seismic deformation modes of reinforced-soil walls. Geotext Geomembr 27:121-136 
23. Huang C-C (2013) Vertical acceleration response of horizontally excited reinforced soil walls. Geosynth Int 20(1):1-12

24. Yogendrakumar M, Bathurst RJ, Finn WDL (1992) Dynamic response analysis of reinforced soil retaining wall. J Geotech Eng (ASCE) 118(8):1158-1167

25. Cai Z, Bathurst RJ (1995) Seismic response analysis of geosynthetic reinforced soil segmental retaining walls by finite element method. Comput Geotech 17:523-546

26. Bathurst RJ, Hatami K (1998) Seismic response analysis of a geosynthetic-reinforced soil retaining wall. Geosynth Int 5(1-2):127-166

27. Helwany MB, Budhu M, McCallen D (2001) Seismic analysis of segmental retaining walls. I: model verification. J Geotech Eng (ASCE) 127(9):741-749

28. El-Emam MM, Bathurst RJ, Hatami K, Mashhour MM (2001) Shaking table and numerical modeling of reinforced soil walls. Proceedings of the international symposium on earth reinforcement, vol 1, Kyushu, Japan, pp 329-334

29. Ling HI, Leshchinsky D (2003) Finite element parameter studies of the behavior of segmental block reinforced soil retaining walls. Geosynth Int 10(3):77-94

30. Fakharian K, Attar IH (2007) Static and seismic numerical modeling of geosynthetic-reinforced soil segmental bridge abutments. Geosynth Int 14(4):228-243

31. Lee KZZ, Chang NY, Ho HY (2010) Numerical simulation of geosynthetic-reinforced soil walls under seismic shaking. Geotext Geomembr 28:317-334

32. Krishna AM, Latha GM (2012) Modeling of dynamic response of wrap faced reinforced soil retaining wall. Int J Geomech (ASCE) 12(4):437-450

33. Liu H (2009) Analyzing the reinforcement loads of geosynthetics-reinforced soil walls subject to seismic loading during service life. J Perform Constr Facil (ASCE) 23(5):292-302

34. Liu H, Wang X, Song E (2011) Reinforcement load and deformation mode of geosynthetics-reinforced soil walls subject to seismic loading during service life. Geotext Geomembr 29:1-16

35. Bhattacharjee A, Krishna AM (2012) Development of numerical model of wrap faced walls subjected to seismic excitation. Geosynth Int 19(5):354-369
36. Bhattacharjee A, Krishna AM (2014) Strain behavior of soil and reinforcement in wrap faced reinforced soil walls subjected to seismic excitation. Indian Geotech J. doi:10.1007/s40098-0140139-x

37. Itasca (2008) Fast Lagrangian analysis of Continua3D version 3.1. Itasca Consulting Group Inc., Minneapolis

38. Duncan JM, Byrne P, Wong KS, Mabry P (1980) Strength, stress, strain and bulk modulus parameters for finite element analyses of stresses and movements in soil masses. Report No. UCB/GT/8001, Department of Civil Engineering, University of California, Berkeley

39. Hatami K, Bathurst RJ (2005) Development and verification of a numerical model for the analysis of geosynthetic-reinforced soil segmental walls under working stress conditions. Can Geotech J 42(4):1066-1085

40. Masing G(1926) Eignespannungen und verfestigungbeim messing. In: Second international congress on applied mechanics, Zurich, Switzerland, pp 332-335

41. Liu H, Ling HI (2012) Seismic response of reinforced soil retaining walls and strain-softening of backfill soil. Int J Geomech (ASCE) 12(4):351-356

42. El-Emam MM, Bathurst RJ (2004) Experimental design, instrumentation and interpretation of reinforced soil wall response using a shaking table. Int J Phys Model Geotech 4:13-32

43. AASHTO (2002) Standard specifications for highway bridges, 17th edn. American Association of State Highway and Transportation Officials, Washington, DC

44. Kramer SL (1996) Geotechnical earthquake engineering. Prentice Hall, Upper Saddle River, NJ (pp 653)

45. Chen WF, Mizuno E (1990) Non-linear analysis in soil mechanics: theory and implementation. Elsevier, Amsterdam

46. FHWA (2001) Mechanically stabilized earth walls and reinforced soil slopes design and construction guidelines. Publication No. FHWA-NHI-00-043. US Department of Federal Highway Administration (FHWA), Washington, DC

47. Wu G (1994) Dynamic soil-structure interaction: pile foundations and retaining structures. $\mathrm{PhD}$ thesis, University of British Columbia, Vancouver, Canada 